\title{
A noção de erro, sinalizador nativo e comunidade de fala na Libras: uma perspectiva sociolinguística
}

Angelica Rodrigues ${ }^{1}$

Anderson Almeida-Silva ${ }^{2}$

\section{Resumo}

Tendo em vista os pressupostos da sociolinguística, formulados no trabalho seminal de Weinreich, Labov e Herzog (2006[1968]), o objetivo deste artigo é fazer uma discussão teórica acerca do conceito de erro linguístico, da definição de falante/sinalizador nativo e comunidade de fala para a comunidade surda que utiliza a Libras (Lingua Brasileira de Sinais). Nossas conclusões apontam para a necessidade de se discutir esses conceitos levando em conta o pressuposto da sociolinguística de que a língua é acima de tudo um construto social.

Palavras-chave: Libras. Sociolinguística. Erro. Comunidade de fala

\footnotetext{
${ }^{1}$ Graduação em Letras pela Universidade Federal de Juiz de Fora (1998), mestrado em Linguística pela Universidade Estadual de Campinas (2001) e doutorado em Linguística pela Universidade Estadual de Campinas (2006), com período sanduíche na Australian National University. Professora Assistente na Faculdade de Ciências e Letras da Unesp - Campus de Araraquara.

2 Doutorando em Linguística pela Universidade Estadual de Campinas. Mestre em Letras - Estudos de Linguagem pela Universidade Federal do Piauí (2013). Especialista em Libras Instituto Federal do Piauí (2009). Professor efetivo na Universidade Federal do Piauí.
}

Revista Leitura v. 1, no 58 - Maceió - Jan./Jun. 2017 - ISSN 2317-9945

Línguas de Sinais: abordagens teóricas e aplicadas, p. 68-91 


\section{Introdução}

O objetivo deste trabalho é discutir o conceito de erro linguístico, a definição de falante/sinalizador nativo e comunidade de fala para a comunidade surda que utiliza a libras, considerando pressupostos da sociolinguística, formulados no trabalho seminal de Weinreich, Labov e Herzog (2006[1968]) (daqui em diante, WLH 2006[1968]). Nessa obra, os autores propõem uma teoria da mudança linguística que contempla o aspecto social das línguas do mundo e o caráter heterogêneo tanto das comunidades de fala quanto do próprio sistema da língua. Nosso foco é investigar como a noção de erro, que não se desassocia das concepções de língua e de comunidade de fala, emerge a partir de comportamentos e opiniões observadas em diferentes espaços, quais sejam didáticopedagógicos (de ensino da Libras), virtual-tecnológico (internet) e literário (publicações sobre a temática) dentro das comunidades surdas, por sujeitos surdos e ouvintes partícipes em situações interacionais diversas.

A discussão leva em conta o pressuposto de que o falante nativo não comete erro para mostrar que na verdade os surdos não cometem erros linguísticos, e que a noção de erro no uso da Libras só seria integralmente aplicável nos contextos em que sinalizadores não nativos (na maioria ouvintes, mas também surdos ou ensurdecidos) estão aprendendo/adquirindo a Libras como segunda língua (L2).

Nesse sentido, considerando que muito se discute na comunidade acadêmica e na comunidade surda sobre a legitimidade de alguns sinais ou mesmo de estruturas morfossintáticas da Libras, propusemo-nos a analisar alguns dados que podem ser representativos dessas polêmicas com o objetivo de oferecer contribuições para a descrição linguística dessa língua sob o viés da Sociolinguística. Estamos cientes de que não é possível esgotar um tema tão complexo em apenas um artigo e, desse modo, limitamo-nos à proposição de, no máximo, uma agenda de estudos de base sociolinguística para a Libras.

Nosso percurso será discutir inicialmente a concepção de língua sob a perspectiva da sociolinguística. Em seguida trataremos do conceito de comunidade de fala e falante nativo na Libras. Em duas seções posteriores, abordaremos a noção de erro tendo em vista os falantes considerados estrangeiros e nativos. Finalizaremos o artigo com uma discussão sobre a percepção da variação e da mudança pelos falantes. Por último, apresentaremos nossas conclusões e as referências. 


\section{A noção de língua para a sociolinguística}

A partir das discussões presentes em WLH (2006[1968]) e das primeiras pesquisas sociolinguísticas empreendidas principalmente por William Labov na década de 1960, é proposto o desenvolvimento de uma perspectiva efetivamente social para a linguística, em que a língua é entendida como um sistema heterogêneo em uso numa comunidade de fala e sujeita a pressões linguísticas e extralinguísticas (sociais).

WLH (2006[1968]) defendem que qualquer análise linguística precisa dar conta daquilo que é parte constitutiva e fundamental de toda língua, a saber, a mudança linguística, e que fora, de certo modo, deixada de lado pelos estruturalistas, ocupados principalmente com a descrição sincrônica.

A problematização da concepção estruturalista de sistema é explicitada na pergunta inicial proposta pelos autores no artigo de 1968: se uma língua tem de ser estruturada, a fim de funcionar eficientemente, como é que as pessoas continuam a falar enquanto a lingua muda, isto é, enquanto passa por períodos de menos sistematicidade? Para WLH, a solução desse dilema seria o rompimento da identificação entre estruturalidade e homogeneidade. Os autores não negam, portanto, a prerrogativa do sistema, mas se esforçam em defender um modelo de análise que dê conta de analisar o sistema heterogêneo da língua. Propõem, portanto, um modelo de análise linguística que seja capaz de descrever a diferenciação ordenada, ou seja, a variação, e sua relação com a mudança linguística, considerando que nem toda variação leva à mudança, mas toda mudança pressupõe um período anterior de variação (WLH, 2006[1968], p. 126). Essa correlação entre variação e mudança linguística instaura um modelo de análise linguística que concebe a língua como um processo dinâmico, em que não é possível a separação de fenômenos diacrônicos e sincrônicos. O estado sincrônico de qualquer língua é resultado dos processos diacrônicos que se sucederam ao longo do tempo. Sendo assim, para WLH, uma análise estritamente sincrônica é uma análise sociolinguisticamente agnóstica.

Para a sociolinguística, não existe língua fora do contexto social e toda língua é um conjunto de variedades; língua é um sistema constituído de heterogeneidade ordenada em que fatores linguísticos e extralinguísticos funcionam como condicionadores da variação e da mudança. A língua, nessa perspectiva, portanto, não pode ser analisada separada dos seus contextos de usos e, consequente, de seus falantes. Considerando que não há língua 
com apenas um falante e que não há gramática individual, as línguas devem ser analisadas no contexto social em que falantes de diferentes idades, origem social, etnia, graus de escolaridade, sexo e gênero interagem.

Desse modo, a gramática não é produto acabado e fechado que esses falantes devem aprender. A gramática é construída justamente por esses falantes em situações de interação em que sentidos são negociados.

\section{Comunidade de fala e o falante nativo na Libras}

A definição do conceito de comunidade de fala não é ponto pacífico na Sociolinguística. Para Labov (2008[1972], p. 150), "a comunidade de fala não é definida por nenhuma concordância marcada no uso de elementos linguísticos, mas sim pela participação num conjunto de normas compartilhadas". Essa definição de comunidade de fala é problematizada em Romaine (1982 apud SEVERO, 2008) que, ao questionar se os membros de uma mesma comunidade utilizariam as regras gramaticais da mesma maneira, indaga se "há realmente comunidades de fala que utilizam regras de gramática da maneira pela qual Labov teria nos feito crer". O que observamos a partir das ponderações da autora é a defesa da heterogeneidade da comunidade de fala, na medida em que propõe que "as fronteiras entre comunidades de fala mais do que linguísticas são essencialmente sociais ${ }^{3 "}$ (ROMAINE, 1994, p.22).

Eckert (1996 apud SEVERO, 2008), por sua vez, propõe "o estudo da variação centrado nas comunidades de prática, nas quais os indivíduos, ao escolherem pertencer a esta ou àquela comunidade, compartilham repertórios de práticas, dentre os quais as linguísticas". Nesse sentido, Severo (2008) atesta que "se considerarmos a realidade como sendo plural, conflitiva e dinâmica, a comunidade de fala é, por certo, uma abstração teórica".

A partir desses conceitos de comunidade de fala e de prática, podemos propor que a identificação dos membros da comunidade surda como pertencentes a uma comunidade de fala ou de prática deve levar em conta aspectos sociais e não necessariamente linguísticos.

\footnotetext{
${ }^{3}$ No original: "The boundaries between speech communities are essentially social rather than linguistic".
} 
Essas questões nos remetem à própria definição de língua, uma vez que para que possamos definir uma comunidade de fala precisamos saber qual língua é falada nessa comunidade. Se por um lado, intuitivamente, todos sabemos o que é língua, por outro, nem sempre podemos definir os limites dessa língua. Por exemplo, se pensarmos na Língua Portuguesa, nos parece fácil identificar onde é falada no Brasil, pois ela é a língua majoritária e oficial do país. Todavia, assim como essa língua não é falada da mesma maneira nas diversas regiões do país, não devemos esperar que o grupo de seus falantes seja homogêneo. Esse grupo é formado por pessoas que, ou usam o português como primeira e única língua, ou que usam diferentes variedades do português (variedades diatópicas, diastráticas, etc.), ou ainda que podem ser considerados bilíngues em algum grau, dentre outros. Concluímos, portanto, que tanto a noção de língua como de comunidade de fala pressupõe uma constituição heterogênea alicerçada em bases sociais.

Desse modo, ao assumirmos que a comunidade surda brasileira é uma comunidade de fala que usa uma variedade linguística mais ou menos estável, à qual damos o nome de Libras, devemos ter em mente dois pressupostos fundamentais. O primeiro deles diz respeito ao próprio entendimento do que é uma língua, que é definida, no bojo dos trabalhos em Sociolinguística, como uma entidade social e heterogênea. Portanto, essa língua, à qual damos o rótulo de Libras, ainda que possa ser representada por um conjunto de regras compartilhadas por seus falantes, se define antes de qualquer coisa como um construto social (HAUGEN, 2001). Como língua natural, essa língua está, portanto, sujeita a pressões de usos associadas às necessidades comunicativas da comunidade.

O segundo pressuposto diz respeito à noção de comunidade de fala, que deve ser entendida como um grupo de falantes que compartilha uma língua, mas que não precisa necessariamente usar a língua da mesma maneira. Sobretudo, devemos ter em mente também que, no caso da comunidade surda, estamos lidando com outro aspecto de heterogeneidade, que diz respeito ao nível de proficiência do indivíduo surdo sinalizante, que, por fatores externos, adquire a língua em condições e períodos distintos. Não se deve desconsiderar também a realidade de línguas de sinais emergentes, que apresentam um uso familiar e mais restrito. A discussão acerca desse aspecto foge ao tema do artigo e é complexa demais; não será explorada aqui em profundidade. Discussões sobre esse tema podem ser encontradas, a título de exemplo, em Fusellier-Souza (2012). No entanto, antes de simplesmente assumirmos que a comunidade surda é uma comunidade de fala 
heterogênea como todas as demais, faremos uma explanação sobre porque entendemos todos os usuários da Libras como falantes nativos da língua.

No que diz respeito à realidade sociolinguística da comunidade surda, consideramos membro da comunidade de fala qualquer surdo que utiliza a Libras no seu dia-a-dia como sua língua de expressão, pois, já que não podemos eleger o sinalizador nativo "padrão", também não podemos criar perfis exclusivos para aceitar/rejeitar um falante como sendo pertencente a essa comunidade. Ou seja, o conceito de sinalizador nativo será variável e dependente essencialmente da possibilidade do indivíduo se integrar a uma comunidade linguística.

Não devemos, todavia, desconsiderar a "geografia" que a Libras assume em relação à dispersão de sua comunidade de fala, o que tem influência direta na forma como a língua está disponível para aquisição e como seus usuários a colocam em prática por meio de atividades sociais. Esse aspecto deve ser descrito como mais um aspecto da heterogeneidade dessa comunidade.

A comunidade de surdos brasileira é heterogênea não só em relação a sua disposição geográfica, mas também em relação ao momento de aquisição da língua, o que cria contextos diversos como: surdos filhos de surdos sinalizadores (que seriam, supostamente, os únicos nativos), surdos filhos de surdos oralizados ${ }^{4}$ e sinalizadores, surdos filhos de surdos oralizados e não sinalizadores, surdos filhos de ouvintes sinalizadores, surdos filhos de ouvintes não sinalizadores, ou ainda a mistura desses perfis que talvez não tenhamos contemplado nessa breve classificação.

Portanto, a comunidade surda apresenta idiossincrasias em termos de definição de sua proficiência pelas questões geográficas e de aquisição. Ou seja, para o falante de português brasileiro (PB), partimos do pressuposto que todos os falantes têm o mesmo nível de proficiência na língua, pois, a priori, todos estão situados em uma comunidade de fala e adquiriram sua língua materna em condições bastante similares, o que não é verdade para os sujeitos surdos.

Entendemos que o conceito de nativo nas línguas orais surge bastante atrelado aos conceitos de período crítico e sensível para a aquisição, ou seja, nativo seria aquele

\footnotetext{
${ }^{4}$ Generalizamos o termo oralizado para o uso de qualquer método oral independentemente da técnica ou tecnologia utilizada.
} 
indivíduo que teria sido exposto à(s) sua(s) língua(s) nativas em idade típica, de 0-5 anos geralmente, e que atrasos nessa exposição poderiam causar danos irreversíveis ao sistema linguístico e cognitivo desse indivíduo, como se pode atestar nos estudos que descrevem situações de crianças que sofreram algum tipo de negligência linguística, ficando isoladas do input auditivo, e que tiveram consequências graves para o seu processo de aquisição (FROMKIN et al., 1974). No entanto, nunca se constataram na literatura casos de surdos que ficaram completamente isolados do input visual. Contrariamente, os gestos caseiros parecem funcionar como uma forma de input visual com uma sintaxe rudimentar (como apontam os estudos de GOLDIN-MEADOW e FELDMAN, 1977), fazendo com que a gramática possa se fixar apesar do atraso com que os surdos são expostos às línguas de sinais, e ainda às condições adversas em que sobrevivem essas comunidades. Portanto, os surdos parecem provisoriamente desenvolver um sistema de comunicação aproximado de uma língua, até que tenham contato com um modelo de língua padrão.

Atesta-se que 95\% dos surdos são filhos de pais sem problemas auditivos (GODINHO, KEOGH \& EAVEY, 2003, p. 103) e a média de idade da detecção da surdez fica entre 3 a 5 anos. Somado a esses fatos, não sabemos a que tipo de input cada um desses surdos teve acesso primeiro: gestos caseiros (mais prováveis), língua escrita, língua oral falada através da oralização ou outros? Ou seja, no caso do Brasil, há uma questão grave em se dizer que a maioria dos surdos que compõem a comunidade surda brasileira não seriam usuários nativos da Libras, e afirmar que somente os outros $5 \%$, que são filhos de surdos, seriam de fato, os usuários nativos.

De fato, observando os surdos utilizarem a sua língua, não é possível detectar se o indivíduo é filho de surdos ou de ouvintes, o que se percebe é uma janela de variação (geralmente lexical) maior do que aquela percebida nas línguas orais, que acentua as diferenças da ordem da variação, e pouquíssimo relacionado com o fato da natividadeparentalidade surda. As diferenças nas sinalizações se dão muito mais em função da dispersão e da heterogeneidade de comunidades de prática que compõem a comunidade surda brasileira atual. Seria inviável buscar onde estão os $5 \%$ de surdos filhos de surdos e ter com isso um critério para estabelecer a natividade do sujeito.

Em face das discussões teóricas apresentadas na seção anterior sobre as comunidades de fala e de prática e dos dados apresentados acima, neste texto sugerimos 
um alargamento do conceito de usuário nativo, que fica muito próximo ao conceito simples de usuário.

Outro risco seria difundir a falsa ideia de que somente surdos filhos de surdos poderiam, por exemplo, dar julgamentos de gramaticalidade sobre a Libras, ou ainda, tornar isso um critério para a coleta de dados nas pesquisas em linguística ou outras áreas. Pesquisas como a de Souza (2016) mostram que surdos filhos de surdos e filhos de ouvintes não apresentam diferenças significativas em julgamentos de fenômenos gramaticais específicos. Somado a esses fatos, podemos estar diante de um fenômeno que não cabe comparação com o conceito de nativo para as línguas orais, já que o processo de aquisição de surdos e ouvintes, apesar das semelhanças nas fases do desenvolvimento, diferencia-se em relação à gradiência da imersão do indivíduo no contexto linguístico.

Não nos parece acurado atribuir aos indivíduos que compõem a maioria dos falantes da língua o rótulo de não nativos. Algum falante monolíngue de qualquer língua do mundo produz sentenças agramaticais, em oposição à ininteligibilidade que pode estar relacionada à variação? Entendemos que esta é uma questão para a qual não temos uma resposta definitiva, mas sinalizarmos para estes fatos dentro desse texto nos parece algo relevante.

Portanto, devemos dizer que a influência do português (diferentemente do português sinalizado, ver exemplos na seção seguinte), muitas vezes encontrado na fala de surdos escolarizados, é tratada nesse texto como uma questão de variação e não de erro, já que apesar da variação aparentemente diafásica, os falantes se entendem, e essa heterogeneidade é esperada dentro dessa comunidade, principalmente se tomamos comunidades bilíngues como a comunidade surda.

Quadros e Cruz (2011), por exemplo, criaram um instrumento de avaliação de língua de sinais que objetiva especificamente avaliar a proficiência de surdos brasileiros na Libras. A partir dessa avaliação, são propostas atividades de intervenção pedagógica que visam suprir a carência do indivíduo das estruturas para as quais são atestadas maior dificuldade durante a compreensão ou produção da Libras, que podem ser lexicais ou mesmo gramaticais. Reiteramos que um instrumento desse tipo é praticamente impensável para a comunidade de fala oral, a menos que: (i) o indivíduo possua algum tipo de distúrbio de linguagem, e seja necessário atestar/contabilizar a "quantidade" de língua que ele 
domina, ou ainda (ii) que o indivíduo tenha sido submetido a uma situação de negligência linguística, ou seja, o isolamento completo da sociedade, o que impediria a aquisição de sua língua materna.

Portanto, surdos de um mesmo ambiente podem possuir níveis distintos de proficiência na sua língua, o que atesta que os surdos são um grupo heterogêneo relacionado à sua comunidade de fala e de prática. Tendo em vista essa heterogeneidade, não é possível distinguir surdos que "sabem" daqueles que "não sabem" Libras de acordo com uma concepção sociolinguística da Libras e da comunidade de fala, já que, no caso da testagem feita por Quadros \& Cruz (2011), surdos que desconhecem totalmente a Libras sequer conseguiriam responder ao teste.

Em pesquisa sobre a concordância verbal nas línguas de sinais, Gaurav e Rathman (2006 apud COSTELLO et al., 2008) consideram sujeitos de pesquisa, ou informantes, aqueles que pelo menos: (i) tenham sido expostos a uma língua de sinais antes dos 3 anos, (ii) tenham habilidade em julgar uma sentença como gramatical e (iii) tenham contato com a comunidade surda pelo tempo mínimo de 10 anos. Além disso, os autores questionam se seria correto definirmos sinalizadores nativos a partir de comportamentos extralinguísticos, como sendo: "filho de", "de tal comunidade", mas muito pouco amparado sobre: "como se fala", ou "quanto se sabe" da língua (o que certamente não seria fácil avaliar). Os procedimentos metodológicos propostos pelos autores levam em conta parâmetros similares aos adotados nas pesquisas sociolinguísticas das línguas orais (TARALLO, 2005) e o uso e o tempo de contato com a língua e com a comunidade de fala.

Não há também como garantir que os surdos filhos de surdos sinalizadores não serão oralizados, e, em pouco tempo, podem demonstrar variação decorrente do contato com a língua oral ou ainda com surdos de outras regiões. É importante considerarmos as características do grupo que compõe a maioria dos surdos que utilizam a Libras em seu diaa-dia e a partir dele elaborar perfis relativamente estáveis de sinalização nativa (que nada tem a ver com purismo linguístico), que pode, inclusive, variar em contextos sociais e geográficos e incluir em sua elaboração padrões linguísticos e extralinguísticos.

Sustentamos, pois, que os usuários de uma língua (falantes nativos) não cometem erros, no sentido de que não produzem sentenças agramaticais ou sem sentido. Usos considerados por alguns falantes como "atípicos", ou "estranhos" devem ser analisados 
com cautela, uma vez que podem ser resultado de processos de variação diatópica, diafásica, diamésica ou diacrônica ou ainda efeito de bilinguismo em algum grau e traços de uma língua de sinais emergente.

\section{Falantes estrangeiros e a noção de erro}

No contexto da comunidade surda, consideramos falantes estrangeiros ${ }^{5}$ aqueles que aprendem, aprenderam ou utilizam a Libras como uma segunda língua. Ou seja, ser um falante de Libras como L2 não tem uma relação imediata com a condição auditiva do indivíduo. Podemos ter ouvintes, surdos ou ensurdecidos que não utilizam a Libras como L1, mas como L2.

Como já mencionado, esse grupo de usuários/aprendizes são os que se encontram mais vulneráveis ao cometimento de "erros" reais no uso da Libras, já que a língua não foi adquirida como uma língua materna. Esse falante tem a Libras como língua estrangeira, e como aprendiz de outra língua, ele trabalha para reafixar os valores contidos nessa nova gramática. Além disso, soma-se o fato de que a Libras é uma língua de outra modalidade.

Portanto, a noção de que exista alguma produção que possa ser considerada "errada" em Libras pode aplicar-se apenas a esse grupo, uma vez que estão em processo de aprendizagem de uma nova língua. No esforço de habilitar outros articuladores (sistema motor e visual) para a produção linguística, é esperado que esses sujeitos "errem" ou, no mínimo, se sintam hesitantes durante esse processo.

A seguir, explicitaremos alguns exemplos do que estamos chamando de "erros" cometidos por falantes estrangeiros da Libras, considerando variáveis de alguns dos níveis linguísticos:

- Português sinalizado: O rótulo "português sinalizado" é usado para se referir àquilo que representaria uma tradução literal da informação em português para a libras. Pode-se comparar, por exemplo, com a tradução literal de frases do inglês para o português, sem que sejam consideradas suas especificidades em qualquer um

\footnotetext{
${ }^{5}$ Utilizamos o termo estrangeiro para se opor ao termo nativo, mas aqui ele tem o mesmo valor de falante de uma segunda língua. Porque nem sempre coincide de que o falante tenha uma segunda língua e essa seja sua língua estrangeira.
} 
dos níveis linguísticos. Nos exemplos abaixo, apresentamos alguns casos representativos do que pode ser entendido como "português sinalizado"6:

(1) PB: O Patinho feio > LIBRAS: *O PATO FEI@ ${ }^{7}$

No exemplo (1), identificamos algo que poderia ser analisado como um tipo de erro que se refere à impossibilidade sincrônica de que um sintagma nominal na Libras seja iniciado pela letra $\mathrm{O}$ do alfabeto, o que seria uma transliteração do artigo definido do português. Pesquisas recentes na Libras apontam que nomes definidos podem ser realizados acompanhados de determinantes como a apontação, como proposto por Almeida-Silva (2013), ou nus, desacompanhados de determinantes, mas nunca com a letra O encabeçando a posição de artigo literalmente. Portanto, esse é um tipo de erro que ocorre no nível morfossintático, geralmente cometido por falantes estrangeiros por desconhecerem os itens lexicais da Libras e ainda, a composição sintática do sintagma nominal nessa língua. É importante destacar que essa conceituação de erro é subjetiva, na medida em que leva em conta uma percepção da comunidade surda que, além de rejeitá-la, parece não usar, de um modo geral, artigos na Libras.

(2) PB: O copo caiu e derramou a água $>$

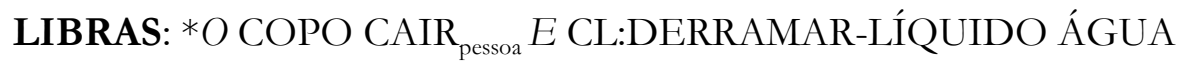

Em (2), destacamos outro erro que poderia ocorrer no nível morfossintático, relativo às construções com verbos classificadores. Os verbos classificadores são complexos informacionais, nos quais, através da configuração de mão selecionada e do tipo de movimento aplicado, é possível se depreender os atributos do objeto (nome) e a ação efetuada por ele. Esse tipo de construção é muito comum em sentenças intransitivas inergativas, mas podem também ocorrer com outros tipos de verbos. Mais uma vez, é possível pensar que aqueles falantes considerados estrangeiros poderiam fazer uma tradução literal para a Libras sem se reestruturar a mensagem a partir do locus espacial. Nesse caso, o resultado seria a má formação da sentença, onde, em sequência: não deveria

\footnotetext{
${ }^{6}$ Nota sobre as glosas em libras: 1. Sinais são representados em letras maiúsculas ex: HOMEM, CASA; 2. Sinais que não flexionam para gênero são marcados com @ ex: FEI@, PROFESSOR@, 3. Uso da soletração manual é representado em itálico ex: O-I, $A, V-I-U$, 4 . A concordância pessoal é feita através de movimentos no espaço e é representada por siglas subscritas, ex: ${ }_{1 s} \mathrm{DAR}_{2 \mathrm{~s}}$ (significa: Eu te dou) e ${ }_{3 \mathrm{~s}} \mathrm{DAR}_{1 \mathrm{~s}}$ (significa: Ela me dá). As pessoas do singular são (1s, 2s, 3s) e do plural (1p, 2p, 3p), 5. CL é utilizado para formas manuais que são classificadoras.

${ }^{7}$ Não falaremos sobre os possíveis morfemas corporais que codificam o diminutivo na língua, pois as ocorrências expostas já são suficientes para se elucidar o fenômeno em tópico.
} 
haver o artigo definido na forma literal da letra $\mathrm{O}$; o verbo e o nome deveriam ser realizados na forma de um classificador, pois o verbo CAIR em Libras não é polissêmico nesses contextos, ele deveria necessariamente incorporar o objeto que está caindo e, atualmente, não há uma conjunção coordenada aditiva gramaticalizada na língua.

(3) PB: Ele canta alto > LIBRAS: EL@CANTAR ALT@ ${ }_{\text {estatura-fisica }}$

Em (3), por sua vez, não parece haver nenhum erro de ordem morfossintática, pois, a priori, a ordem SVO é a ordem básica na Libras (QUADROS, 1999). No entanto, poderíamos pensar em um erro de ordem semântica, pois, na busca por sentenças equivalentes para as línguas, se utiliza um adjetivo que não apresenta a polissemia disponível no mesmo adjetivo em português. Ou seja, o adjetivo ALTO $\mathrm{estatura-fisica}_{\text {em Libras }}$ só pode ser aplicado a coisas literalmente altas, no sentido físico, de estatura, do mundo físico. Para utilizar um sinal que se referisse a "alto" no sentido de volume, de intensidade de ondas sonoras, como se pretende na sentença em destaque, teríamos que fazer uso de um classificador que traz a ideia de subir/elevar, e que também poderia ser traduzido como alto (em PB), embora cada sinal tenha um contexto específico de uso. Por isso, nesse caso, o conhecimento semântico e até mesmo pragmático da língua é necessário para que não se produzam estruturas não verificáveis no uso da língua por parte da comunidade de fala.

Considerados os exemplos anteriores, cumpre ressaltar que apenas a partir de um bom inventário de estruturas dessa língua poderíamos apontar com mais segurança aquilo que é ou não usado pelos membros da comunidade de fala. Isso porque fora do uso não é possível falar em erro, já que muitas estruturas classificadas como "erro" numa determinada língua são, de fato, atestadas, representando, na verdade, estruturas não padrão. Outra questão diz respeito ao fato de que a mudança linguística pode ter como efeito estruturas que foram, em sincronia anterior, inaceitáveis. A título de exemplo, podemos citar o caso do uso do verbo ir na perífrase de futuro no português. Como verbo pleno, IR só admite sujeitos animados, mas na construção de futuro, esse verbo passa, via gramaticalização, a aceitar sujeitos com traço [- animado], como em "O prédio vai cair". Desse modo, enfatizamos que falar em "erro", segundo uma concepção sociolinguística da língua, pressupõe um estudo mais aprofundado das variedades em uso na comunidade de fala. 


\section{- Troca de parâmetros fonológicos}

$\mathrm{Na}$ Libras, a orientação funciona como um fonema e é distintivo para alguns pares de sinais. Entre os sinais de "INTÉRPRETE" e "CUNHADO ${ }^{8}$ ", por exemplo, o único traço distintivo é a orientação da palma da mão não dominante, que naquele é para cima, e neste último é para baixo. Então, em Libras pode-se realizar o sinal de CURSO, variando o fonema ponto de articulação entre iniciar o movimento de deslizar no ombro, no cotovelo, ou mesmo no pulso, mas não pode, por exemplo, fazer o caminho contrário do movimento, do pulso para o ombro, ou do cotovelo para o ombro como previsto em análises de variação fonológica como a de Xavier (2014). Por isso, apesar da possível variação que neutraliza as oposições na língua, o que poderia se considerar como a realização de uma variante alofônica ${ }^{9}$, nem toda variação teoricamente possível é atestada e reconhecida como parte da língua, sendo, portanto, os casos de erro.

Esses usos poderiam ser considerados erros na medida em que não são atestados na fala de indivíduos surdos falantes da língua como L1. E, se algumas dessas ou de outras estruturas começarem a aparecer no uso da língua, é preciso submetê-las à análise para investigar se se trata de um estágio de variação no dialeto, que pode ou não desencadear uma mudança na língua. Todavia, essas mudanças só podem ser implementadas ou não na língua pelos seus usuários reais e não por falantes estrangeiros. É disso que trataremos com mais detalhes na próxima seção.

\section{Falantes nativos e a noção de erro}

Por questões metodológicas e baseados nas questões teóricas expostas na seção anterior sobre a eleição do sinalizador nativo, reconhecemos, neste trabalho, que os sinalizadores nativos seriam todos os surdos que se comunicam prioritariamente pela Libras, independentemente dos contextos de aquisição da língua e do dialeto a que pertencem.

\footnotetext{
${ }^{8} \mathrm{Em}$ algumas variedades, mas não em todas, pois em alguns lugares o sinal de cunhado é feito com a mão em C, e, portanto, não forma um par mínimo com o sinal "INTÉRPRETE".

${ }^{9}$ Não há estudos específicos sobre essas classes de fonemas na Libras. O que se sabe sobre a aceitabilidade de variação na gradiência de realização de alguns sinais vem de estudos de variação fonológica (XAVIER, 2014), mas não sobre um estudo da classe fonológica per si.
} 
A priori, quando os surdos brasileiros dizem que um determinado grupo de surdos utiliza a língua de forma "errada", estão, na verdade, baseando-se numa avaliação subjetiva, que é, muitas vezes, reflexo de algum aspecto de estratificação social. Por isso, nos próximos parágrafos empreenderemos uma análise sobre como a avaliação social, que nunca está desassociada da percepção dos falantes em relação a determinadas estruturas da língua, é mais saliente nos contextos em que se acusam um determinado grupo de "falar errado", no caso, a Libras.

Para qualquer língua em uso, oral ou sinalizada, não há, segundo os pressupostos labovianos (LABOV, 2008[1972]), nada na estrutura linguística que possa sustentar a eleição de formas variantes como variante de prestígio ou estigmatizada. Não há nada imanente na sonoridade de uma classe fonológica, como nos casos de "bicicreta" e "bicicleta" do português, que preveja a estigmatização do rótico ou da lateral, nem mesmo na variação encontrada em flexões verbais como em "Ela canta" e "Elas cantaØ”. Ou seja, o processo de avaliação das formas linguísticas se faz dentro da comunidade de fala, muitas vezes, sob efeitos da escolarização, uma vez que, na visão tradicional da língua, é possível atribuir às estruturas da língua rótulos como "feio", "errado" ou "bonito" e "certo". Nesse caso, tomam-se como referência algumas estruturas da língua em uso em contexto literário basicamente para propor um padrão linguístico que deve ser seguido por todos os falantes em todas as situações de interação.

Essa prática pedagógica propõe, portanto, a correção das formas alternativas numa tentativa de homogeneização da língua, sustentada na crença de que "a língua" está representada nos manuais de gramática. Por considerar que a gramática tradicional não pode dar conta da língua em todas as suas formas de expressão e uso, Faraco (2008) usa o conceito de "norma curta" para se referir às normas que a gramática tradicional apresenta como sendo a "norma culta" da língua, mas que não dão conta da língua assim como é usada inclusive por falantes considerados cultos (mais escolarizados).

Cumpre ressaltar que essa "defesa" que a gramática tradicional faz de determinadas estruturas em detrimento de outras igualmente em uso pela comunidade de fala não se sustenta cientificamente. Portanto, mais do que por rigor científico, a gramática tradicional opera muitas vezes num outro domínio, em que pesam critérios linguísticos poucos claros. Por essa razão, assumimos que o pensamento tradicional sobre a língua sustenta-se apenas numa crença de que há estruturas "certas" e estruturas "erradas" nas línguas. É uma crença 
virtual e independente, que, embora seja mais forte em relação às línguas de cultura, que dão à escrita estatuto superior à fala, também vigora na comunidade surda, por exemplo. Prova disso é a tentativa de aplicar esses julgamentos em línguas de sinais, que não são línguas com cultura de escrita e que nem por isso estão imunes a essas noções de "certo" e "errado". Por trás desse pensamento, está a crença de que a língua é homogênea e estável.

Ainda que não existam modelos prescritivos para a Libras, os materiais didáticos, como apostilas, são muitas vezes elaborados segundo essa perspectiva, ou crença, tradicional sobre a língua. Ademais, essa noção de "certo" e "errado" varia nas publicações locais ou nacionais de acordo com o julgamento que mais se aproxima daquela variedade da língua que é tomada como referência, evidenciando o caráter assistemático dessas análises.

Sendo assim, do mesmo modo que defendemos a necessidade de pesquisas mais amplas de descrição da Libras, que poderiam levar enfim à elaboração de uma gramática descritiva dessa língua, devemos também destacar que a comunidade surda não precisa de uma gramática que seja elaborada apenas com o intuito de definir padrões de uso que poderão fundamentar a estigmatização de variedades dessa língua.

Sabemos que essa tem sido a função da gramática tradicional nas atividades de ensino e aprendizagem do português para ouvintes, que baseados, nessas práticas, "transferem" esse comportamento para as práticas de ensino e aprendizagem da Libras. Isso invariavelmente fomenta um comportamento de estigmatização e julgamento das variedades que se distanciam daquelas adquiridas por meio dos cursos de Libras. O que acontece é que muitas vezes o aprendiz da língua está mais preocupado em julgar formas como "certas" e "erradas" do que em aprender as possibilidades de variação dentro da língua. Nesse sentido, Gesser (2006) explicita várias situações em que alunos ouvintes não aceitam a variação lexical existente na Libras e tomam as formas variantes como "erradas".

Percebe-se, então, que é preciso cautela ao se definir a noção de erro no que se refere aos usos do falante nativo da Libras, já que é preciso garantir antes de qualquer coisa que não estamos diante de casos de variação. Para isso, é fundamental identificar dentro da comunidade de fala os grupos que compartilham ou não a mesma avaliação sobre as formas linguísticas disponíveis e variáveis. 
A título de exemplo, remetemos à discussão de se haver ou não uma distinção entre o sinal para a letra "S" e para o numeral " 8 " na Libras. Sabemos que ambas as formas de se realizar o numeral " 8 " existem na língua, com ou sem o movimento, e que o contexto se encarrega de desambiguizar os sinais possivelmente homônimos, não havendo, portanto, a necessidade de se eleger o sinal certo ou errado. Mas, não é para todos os sinalizadores que os sinais " $\mathrm{S}$ " e " 8 " são homônimos, ou seja, há um grupo que já considera o movimento de "8” como um sinal distinto, embora com a mesma configuração de mão.

E ainda que para os falantes nativos essa avaliação seja inevitável, já que, segundo Labov (2008[1972]), a avaliação é um ponto de convergência entre os membros da comunidade de fala, não devemos promover esse mesmo julgamento em contextos acadêmicos e/ou pedagógicos, sob o risco de fomentar o preconceito linguístico.

Outra questão relevante que precisa ser explorada nesse aspecto são os empréstimos (ou estrangeirismos). Uma postura tradicional tende a rejeitar nas línguas de sinais ou orais a incorporação de elementos provenientes de línguas majoritárias ou estrangeiras. Apesar disso, a história das línguas atesta que os empréstimos linguísticos são fenômenos naturais e esperados para línguas que estão em contato, direto ou não. A ideia de uma língua pura, sem mesclas ou misturas só existe no imaginário dos seus usuários, ou seja, é uma realidade que não pode ser atestada empiricamente. No que tange às línguas de sinais, Souza e Segala (2009) salientam que seus contextos de surgimentos remetem a influências e misturas em relação a outras línguas. $O$ mesmo vale para as línguas orais. A emergência de línguas pidgins e crioulas nos dão a medida de como novas línguas nascem e de que esse nascimento é marcado pelo contato linguístico.

No que tange às línguas sinalizadas, uma das formas mais comuns de empréstimo diz respeito ao uso da datilologia. Em relação ao uso de sinais baseados em datilologia, Valli e Lucas (1992, p. 41) enfatizam que empréstimos de datilologia são reestruturados para se adequar à fonologia da língua de sinais. Waters et al. (2007, p. 1287), por seu turno, investigaram como a lateralidade cerebral processa palavras escritas, imagens, sinais e datilologia, e se datilologia era de fato processada como escrita ou sinalização. Os autores observaram que datilologia é processada em áreas do cérebro similares às usadas para línguas de sinais e distintas daquelas envolvidas em escrita. Tratando especificamente de aquisição, Padden e LeMaster (1985), Akamatsu (1985), e Blumenthal-Kelly (1995) apontam que crianças reconhecem "palavras soletradas" manualmente muito antes de 
aprenderem a "soletrar", o que pode evidenciar que essas palavras soletradas são consideradas sinais e não palavras transliteradas da língua oral.

Devemos entender que, muitas vezes, essa postura em relação a possíveis empréstimos do português em uso na Libras é efeito de "traumas" causados pela pedagogia oralista, que tentava a todo custo forçar a fala oral de sujeitos surdos, que, por sua vez, não podiam usar livremente a língua sinalizada. Todavia, o processo linguístico natural de intercâmbio entre línguas em contato deve ser entendido para além da escola oralista se o objetivo do linguista é dar conta da estrutura das línguas de sinais, que, como línguas naturais que são, constituem-se na heterogeneidade. A linguística, uma vez que assume que as línguas de sinais estão sujeitas aos mesmos processos de variação e mudança largamente descritos para as línguas orais, afasta-se do pensamento tradicional oralista de que o surdo depende da língua oral para "exercer sua faculdade de linguagem" para apresentar subsídios que podem, inclusive, promover a defesa da autonomia das línguas sinalizadas como línguas potentes e suficientes para embasar a linguagem e o pensamento humano e, sobretudo, para agir e interagir nos meios sociais.

Alguns exemplos de variação na Libras são rotulados como "coisa de ouvinte", sob a justificativa de que "surdos não falam isso". A confirmação ou não desse tipo de hipótese só será possível a partir de evidências empíricas analisadas em pesquisas acerca de "como os surdos usam a sua língua" em contextos diversos e na interação entre surdos e surdos e ouvintes, sem deixar de considerar os fatores linguísticos e extralinguísticos (sexo/gênero, escolaridade e idade, por exemplo).

Alguns trabalhos apontam para resultados dessa natureza, como o de Silva (2013), que descreve a variação diafásica observável entre surdos no uso da Libras em contextos formais e informais. Os contextos formais são geralmente os contextos em que a língua tem mais visibilidade, como por exemplo, os editais do Prolibras, os vídeos institucionais do INES, o edital do ENEM, os vídeos do curso de Letras-Libras da UFSC, etc. Os resultados apresentados apontam para a variação de registro no uso da Libras, algo que certamente precisa ser investigado com mais profundidade.

Variáveis como formalidade versus informalidade e escolaridade devem ser consideradas na análise de fenômenos como "criação de sinais" ou inovações utilizadas por grupos específicos. É interessante observar que, diferentemente do que pressupõe Labov 
(2008[1972]) para as línguas orais, nas quais as formas inovadoras tendem a emergir na fala informal de grupos intermediários, de escolaridade mais baixa, no que diz respeito às línguas de sinais, as pesquisas realizadas até o momento (JOHNSTON; SCHEMBRI, 2007) fazem referência a processos de mudança iniciados apenas por usuários mais escolarizados que, aparentemente, tendem a incorporar mais facilmente elementos inovadores na língua, principalmente por influência da língua oral. Dentre esses elementos destacamos o uso de conjunções e preposições, e a criação de sinais nos glossários de área. No entanto, no que concerne à Libras, somente uma pesquisa subsidiada pela análise de um corpus que considere a variante escolarização poderia confirmar os apontamentos aqui realizados.

$\mathrm{Na}$ próxima seção discutiremos sobre quais são os espaços que estão disponíveis para que essa avaliação entre os falares seja exercida nas comunidades usuárias de libras e quais tipos de variação já podem ser percebidas na língua.

\section{Onde e quando percebemos a variação e a mudança?}

Segundo Faraco (2005), há algumas situações específicas que favorecem a percepção da variação e da mudança por parte dos falantes. Uma delas é no contraste entre as manifestações linguísticas afastadas entre si no tempo, definida como "mudança em tempo real". Outra maneira é a percepção de fenômenos de mudança concentrando nossa atenção no tempo presente, isto é, a "mudança em tempo aparente".

São, portanto, nesses contextos de contraste entre formas variantes que os falantes se dão conta de que sua língua mudou. No que diz respeito à Libras, gostaríamos de citar alguns casos de variação que, embora não tenham sido observados a partir de análise sistemática, mas a partir do contato dos pesquisadores com a língua, podem ser confirmados ou verificados, a depender do conhecimento dos leitores sobre a língua.

Para além da variação fonológica encontrada na Libras já atestada por estudos anteriores, como os de Andrade (2013) e Xavier (2014), apresentamos o que parecem ser casos de variação no nível morfossintático. O primeiro deles diz respeito ao uso de preposições. 
A Libras possui um repertório pequeno de preposições se comparada ao PB e muito pouco se sabe sobre elas. Um item candidato à preposição em Libras, e que é utilizado em alguns contextos, principalmente dento do domínio nominal é o sinal PARA (configuração de mão em $\mathrm{P}$, movimento direcional para frente a partir da testa). Provavelmente o uso do PARA, assim como os outros casos, em Libras, deve-se ao contato com a língua oral, pois representaria uma inovação na língua, responsável, por exemplo, pela marcação do objeto indireto na posição junto ao verbo.

Assim como no inglês $\mathrm{I}_{\mathrm{SUJ}}$ gave her $\mathrm{OI}_{\mathrm{O}}$ the book $_{\mathrm{OD}}$, na Libras teríamos algo do tipo $\mathrm{EU}_{\mathrm{SUj}}$ DAREL@ ${ }_{\mathrm{OI}}$ LIVRO $_{\mathrm{OD}}$ onde o objeto indireto do verbo recebe seu caso junto ao verbo, e não por meio de uma preposição, como em outras línguas, como o português. Ou seja, a Libras não permite algo como *EU DAR LIVRO ELA em que o objeto indireto está distante do verbo.

Mais recentemente temos observado o uso da preposição PARA em Libras para marcar o objeto indireto em sentenças como $E_{\text {SU }} D_{\text {DAR }}$ LIVRO $_{\mathrm{OD}}$ PARA ELA ${ }_{\mathrm{OI}}$. Esse tipo de sentença começa a ser observada em contextos em que os indivíduos geralmente querem fazer uma afirmação categórica sobre algo, utilizando inclusive, a preposição PARA, que parece já ter sido de certo modo incorporada ao léxico da língua. Essa variação (presença ou ausência de PARA na introdução de objeto indireto) na Libras pode ou não culminar em mudança. A depender dos falantes, essa forma pode ser implementada ou não. Cabe ao sociolinguista mapear os contextos de uso desse "candidato" à preposição, observando os fatores linguísticos e extralinguísticos associados a esse uso. Isso porque se por um lado a avaliação positiva ou negativa é natural nos falantes, como pesquisador, o linguista não deve emitir juízos de valor em relação aos diferentes usos da língua. Nosso trabalho, diante de casos de variação, é tão somente atestar a mudança em tempo real, confrontando dados de sincronias distintas, ou levantar hipóteses acerca da implementação da mudança com base na metodologia, proposta por Labov, que permite analisar a mudança enquanto ela ocorre numa determinada sincronia através do confronto de dados produzidos por falantes de diferentes faixas etárias (mudança em tempo aparente).

Obviamente os possíveis casos de variação ora destacados demandam inúmeras discussões que o espaço deste artigo não nos permite detalhar. Com essa descrição, almejamos tornar a questão da variação visível e desmistificá-la como sendo uma forma "errada", ou que não é produzida pelos surdos nativos. O que defendemos é que esses 
julgamentos não podem ser utilizados como instrumento de segregação, para a sustentação de um ideal de língua pura, principalmente em contextos pedagógicos. A Libras, como qualquer língua, está sujeita à variação e à mudança, pois variação e mudança são propriedades inerentes das línguas em uso. Uma língua que não muda é uma língua que está morta, o que definitivamente não é o caso da Libras.

Uma forte evidência do fortalecimento da Libras é a sua difusão na internet, que tem se configurado como o espaço de prática para a comunidade de surdos tendo em vista a possibilidade de postagens em vídeo, e considerando que, muitas vezes, os surdos não têm um ambiente linguístico favorável à prática comunicacional no seu ambiente doméstico. Às vezes, esse espaço virtual é utilizado para fomentar a noção de erro, através do julgamento de estruturas linguísticas, principalmente sobre o uso de sinais específicos. Há alguns fóruns de debate de pessoas surdas e ouvintes na internet, onde se discute, por exemplo, qual seria o sinal melhor, ou o mais correto para ser adotado pela comunidade. A crença de que a língua deva ser homogênea é em parte responsável por discussões desse tipo que são, na verdade, infrutíferas no que tange a ideia de "defesa da língua", embora revelem, por outro lado, uma necessidade de seus usuários em compreender suas especificidades e usos.

Nesse sentido, dadas as características da comunidade surda brasileira aqui apresentadas e da ampliação do uso da Libras, nos cursos de graduação, na criação de glossários e outros, há uma preocupação compreensível dos surdos de que sua língua modifique-se tanto a ponto que essas mudanças ameacem o seu domínio ou a própria existência do idioma.

Desse modo, o espaço da internet reflete a constituição dessa comunidade de fala, que, na falta ou na carência de espaço concreto de interação para o exercício da língua cotidianamente, utiliza-se o espaço virtual para compartilhar suas experiências pessoais, sociais e linguísticas. Ou seja, o mundo virtual não se resume a um espaço de homogeneização, de higienização, pois é principalmente um espaço de uso e sobrevivência da língua e elemento agregador dessa comunidade. 


\section{Conclusões}

Ao assumirmos uma perspectiva sociolinguística de língua para o tratamento de aspectos atinentes à Libras, dispusemo-nos a debater o conceito de erro linguístico, a definição de falante/sinalizador nativo e comunidade de fala. Nosso objetivo foi, antes de tudo, lançar luz sobre questões que emergem frequentemente no ambiente pedagógico, dada a proliferação de cursos de Libras, Letras-Libras, dicionários de termos técnicos, dentre outros.

Das discussões apresentadas neste artigo, fica a proposição de uma agenda de estudos descritivos e sociolinguísticos, ainda incipientes, que possam tanto fomentar as atividades pedagógicas de ensino e aprendizagem da Libras quanto apresentar um "retrato sociolinguístico" da língua. Salientamos, contudo, que conhecer a Libras é também conhecer seus falantes, ou seja, a comunidade de fala, tendo em vista seu caráter heterogêneo.

Propomos neste texto uma expansão da aplicação do termo "nativo" para surdos que não tiveram aquisição cediça da Libras, considerando que a maioria dos falantes da língua não tem acesso à língua na tenra infância, mas não fracassam em sua aquisição muito provavelmente em detrimento do uso de outras formas de comunicação que funcionam como uma língua. No entanto, esta é uma conceptualização teórica provisória para o que pode ser o falante nativo nessas comunidades.

A partir disso, discutimos como as possíveis estruturas apontadas como certas ou erradas pelos falantes da língua podem refletir, na verdade, contextos de variação e mudança pelo contato com o português oral. Relegamos ainda os erros de produção aos falantes aprendizes da língua como L2, como resultado de um processo natural de bilinguismo, mas nunca ao grupo que consideramos como falantes nativos.

A visibilidade e diversidade da comunidade surda e a valorização de sua língua e cultura podem ser promovidas com a incorporação dos pressupostos sociolinguísticos, que visam a garantir a legitimidade de todas as formas de uso da língua. 


\section{Referências}

AKAMATSU, C. Tane. Fingerspelling Formulae: a word is more or less than the sum of its letters. In: STOKOE, William; VOLTERRA, Virginia (Org.), Sign Language Research n. 83. Silver Spring, MD: Linstok Press, 1985, p. 126-132.

ALMEIDA-SILVA, Anderson. Sintagmas nominais: semântica da referencialidade e determinação na Libras. Dissertação (Mestrado em Letras). Teresina: Universidade Federal do Piauí, 2013.

ANDRADE, Wagner Teobaldo Lopes de. Variação fonológica da Libras: um estudo sociolinguístico de comunidades surdas da Paraíba. Tese (Doutorado em Linguística). João Pessoa: Universidade Federal da Paraíba, 2013.

BLUMENTHAL-KELLY, Arlene. Fingerspelling interaction: a set of deaf parents and their deaf daughter. In: LUCAS, Ceil (Org.). Sociolinguistics in deaf communities. Washington, DC: Gallaudet University Press, 1995.

COSTELLO, Brendan; FERNÁNDEZ, Javier; LANDA, Alazne. O sinalizador nativo não-(existente). In: QUADROS, Ronice Muller de; VASCONCELLOS, Maria Lúcia Barbosa de (Org.). Questões teóricas das pesquisas em línguas de sinais - TILSR 9. Petrópolis: Arara-azul, 2008.

FARACO. C. A. Linguística histórica: uma introdução ao estudo da história das línguas. São Paulo: Parábola, 2005.

Norma culta brasileira: desatando alguns nós. São Paulo: Parábola, 2008.

FROMKIN, Victoria et al. The development of language in genie: a case of language acquisition beyond the "critical period". Brain and language, v. 1, n. 1, 1974, p. 81-107.

FUSELLIER-SOUZA, I. Multiple perspectives on the emergence and development of human language: B. Comrie, C. Perdue and D. Slobin. In: WATOREK, Marzena; BENAZZO, Sandra; HICKMANN, Maya. Comparative perspectives on language acquisition: a tribute to Clive Perdue. Bristol; Buffalo: Multilingual Matters, 2012, p. 223244, 2012.

GESSER, A. Um olho no professor surdo e outro na caneta: ouvintes aprendendo a Libras. Tese (Doutorado em Linguística Aplicada). Campinas: Universidade Estadual de Campinas, 2006.

GODINHO, Ricardo; KEOGH, Ivan; EAVEY, Roland. Perda auditiva genética. Revista Brasileira de Otorrinolaringologia, v. 69, n. 1, 2003, p. 100-4.

GOLDIN-MEADOW, Susan; FELDMAN, Heidi. The development of language-like communication without a language model. Science, v. 197, n. 4301, 1977, p. 401-403.

HAUGEN, E. Dialeto, língua e nação. In: BAGNO, M. (Org.). Norma linguística. São Paulo: Editora Loyola, 2001, p. 97-114. 
JOHNSTON, T.; SCHEMBRI, A. Australian Sign Language (Auslan). An introduction to Sign Language Linguistics. Cambridge University Press, 2007.

LABOV, W. Padrões sociolinguísticos. Trad. Marcos Bagno, Marta Scherre e Caroline Cardoso. São Paulo: Parábola, 2008[1972].

PADDEN, Carol; LEMASTER, Barbara. An alphabet on hand: the acquisition of fingerspelling in deaf children. Sign Language Studies n. 47, 1985, p. 161-172.

QUADROS, Ronice Muller de. Phrase structure of Brazilian Sign Language. Tese (Doutorado em Linguística e Letras). Porto Alegre: Universidade Católica do Rio Grande do Sul, 1999.

QUADROS, Ronice Müller de; CRUZ, Carina Rabello. Línguas de sinais: instrumentos de avaliação. Porto Alegre: Artmed, 2011.

ROMAINE, S. Language in society: an introduction to Sociolinguistics. Oxford: Oxford University Press, 1994.

SEVERO, C. G. A comunidade de fala na sociolinguística laboviana: algumas reflexões. Voz da Letras n. 9, v. I. Concórdia; Santa Catarina: Universidade do Contestado, 2008.

SILVA, Rodrigo Custódio da. Indicadores de formalidade no gênero monológico em Libras. Dissertação (Mestrado em Linguística). Florianópolis: Universidade Federal de Santa Catarina, 2013.

SOUZA, Isaac Gomes Moraes de. Concordância verbal e a hipótese do período crítico em Libras: um estudo teórico-experimental. Dissertação (Mestrado em Estudos da Línguagem). Rio de Janeiro: Pontifícia Universidade Católica do Rio de Janeiro, 2016.

SOUZA, R. B.; SEGALA, R. R. A perspectiva social na emergência das línguas de sinais: a noção de comunidade de fala e idioleto segundo o modelo teórico laboviano. In: QUADROS, R. M.; STUMPF, M. R. (Org.). Estudos surdos IV. Petrópolis: Arara Azul, 2009 , p. 21-48.

TARALLO, Fernando. A pesquisa sociolinguística. 7 ed. São Paulo: Ática, 2005.

VALLI, Clayton; LUCAS, Ceil. Linguistics of American Sign Language. Washington, DC: Gallaudet University Press, 1992.

XAVIER, André Nogueira. Uma ou duas? Eis a questão! Um estudo do parâmetro número de mãos na produção de sinais da Língua Brasileira de Sinais (Libras). Campinas: Universidade Estadual de Campinas, 2014.

WATERS, Dafydd; CAMPBELL, Ruth; CAPEK, Cheryl; WOLL, Bencie; DAVID, Anthony; MCGUIRE, Philip; BRAMMER, Michael; MACSWEENEY, Mairead. 2007 fingerspelling, signed language, text and picture processing in deaf native signers: the role of the mid-fusiform gyrus. Neuroimage v. 35, 2007, p. 1287-1302. 
WEINREICH, U.; LABOV, W.; HERZOG, M. I. Fundamentos empíricos para uma teoria da mudança linguística. Trad. BAGNO, M. São Paulo: Parábola Editorial, 2006 [1968].

\section{Abstract}

Based on the sociolinguistics theory, in its seminal proposal of Weinreich, Labov \& Herzog (2006 [1968]), this paper aims to discuss the concepts of linguistic error, native speaker/ signer and speech community regarding to the Brazilian deaf community, which uses Libras Brazilian Sign Language). Our findings points out to the necessity of assuming a sociolinguistic view in order to understand language as a social construct.

Key-Words: Libras (Brazilian Sign Language). Sociolinguistic. Linguistic error. Speech community 